\title{
Datos de base de la vega de Antequera y Archidona
}

La zona de la vega de Antequera y Archidona' comprende quince municipios de la provincia de Málaga completos y tres municipios integrados parcialmente. Los municipios que se integran completamente en la zona estudiada son los siguientes: Alameda, Archidona, Cuevas Bajas, Cuevas de San Marcos, Fuente de Piedra, Humilladero, Mollina, Sierra de Yeguas, Valle de Abdalajis, Villanueva de Algaidas, Villanueva del Trabuco y Villanueva de Tapia. Parcialmente se integran los municipios de Antequera, Campillos y Villanueva del Rosario. El total de inmuebles que se localizan en esta zona son 334 de los cuales el $78 \%$ corresponde al patrimonio arqueológico, el 14\% al patrimonio arquitectónico y el $8 \%$ al patrimonio etnológico.

El patrimonio arqueológico localizado en la zona es muy abundante, pues los primeros asentamientos datan del paleolítico medio, aunque es en la Edad del Cobre cuando se producen grandes manifestaciones megalíticas como La Zona Arqueológica de los Dólmenes de Antequera, formada por los dólmenes de Menga, Viera y El Romeral, así como por una serie de yacimientos directamente relacionados con esta necrópolis. Muy próximo a los dólmenes se encuentra el asentamiento del Cerro de Antequera, que es un poblado calcolítico de la etapa campaniforme.

En la época romana se observa que el número de entidades arqueológicas casi se quintuplica con respecto a la prehistoria reciente, debido al intenso proceso de romanización que experimentó todo el territorio andaluz. Entre otros se encuentran la villa romana de La Estación, las Termas de Santa Maria, El Gallumbar, el poblado y necrópolis tardorromana de La Angostura y la ciudad romana de Singilia Barba.
En cuanto al patrimonio arquitectónico se encuentran en esta zona los centros históricos de Antequera y Archidona, declarados BIC como Conjuntos Históricos. Antequera tiene un esplendoroso pasado y se refleja en su patrimonio arquitectónico. Nos encontramos que la mayor parte del patrimonio arquitectónico pertenece a la Edad Moderna, como la Real Colegiata de Santa María La Mayor, primer templo concebido dentro del estilo renacentista de Andalucía y la Real Colegiata de San Sebastián, o el Monasterio de San Zoilo, así como numerosas iglesias y capillas. Es el siglo XVIII cuando la ciudad alcanza su máximo auge; se asientan varias congregaciones religiosas y se construyen numerosos conventos. También la nobleza erige grandes palacios y surge una gran actividad artística. Entre los conventos destacan el de Madre de Dios de Monteagudo, el Convento de San Agustín y el de San José; y, entre los palacios, el de la Marquesa de las Escalonias y el del Marqués de Villadarias.

En el centro histórico de Archidona destacan el CastiIlo y la Puerta del Sol, la Ermita de la Virgen de Gracia y la Plaza Ochavada, de gran belleza arquitectónica.

En cuanto al patrimonio etnológico nos encontramos numerosos edificios agropecuarios repartidos por la vega, dedicados a la producción de cereales y aceite así como varios molinos y almazaras vinculados a estos.

Desde el punto de vista de las tipologías funcionales y los periodos históricos a los que se asocia el patrimonio inmueble de la zona estudiada, se han utilizado los términos del Tesauro de Patrimonio Histórico Andaluz agrupándolos de la siguiente manera:
- Edificaciones productivas; los inmuebles pertenecientes a esta tipología suponen un $53 \%$ del total. - Edificaciones dotacionales, que agrupa distintas tipologias como las construcciones funerarias, sanitarias, de espectáculo, etc. Los inmuebles pertenecientes a esta tipología suponen un $6 \%$ del total.

- Asentamientos y espacios libres; los inmuebles pertenecientes a esta tipología suponen un 17\% del total. - Edificaciones militares; los inmuebles pertenecientes a esta tipología suponen un 6\% del total.

- Edificaciones religiosas; los inmuebles pertenecientes a esta tipología suponen un 12\% del total.

- Edificaciones residenciales; los inmuebles pertenecientes a esta tipología suponen un 4\% del total.

- Sitios con representaciones rupestres; los inmuebles pertenecientes a esta tipología suponen un 1\% del total.

En cuanto a los periodos históricos destacan la Época Romana, con 192 inmuebles, seguidos de la Edad Moderna, con 48 inmuebles, la Prehistoria Reciente, con 40 inmuebles, la Edad Media, con 29 inmuebles, la Protohistoria, con 17, la Edad Contemporánea, con 11 inmuebles y, por último, el Paleolítico, con 10 inmuebles.

Pilar Mondéjar Fernández de Quincoces Salud Soro Cañas

Centro de Documentación y Estudios del IAPH

\section{Nota}

'La información de carácter patrimonial contenida en el Sistema de Información para la Gestión Integral del Patrimonio Cultural relativa a la zona de la vega de Antequera y Archidona se analizará en base al patrimonio inmueble que se haya localizado cartográficamente en la misma.

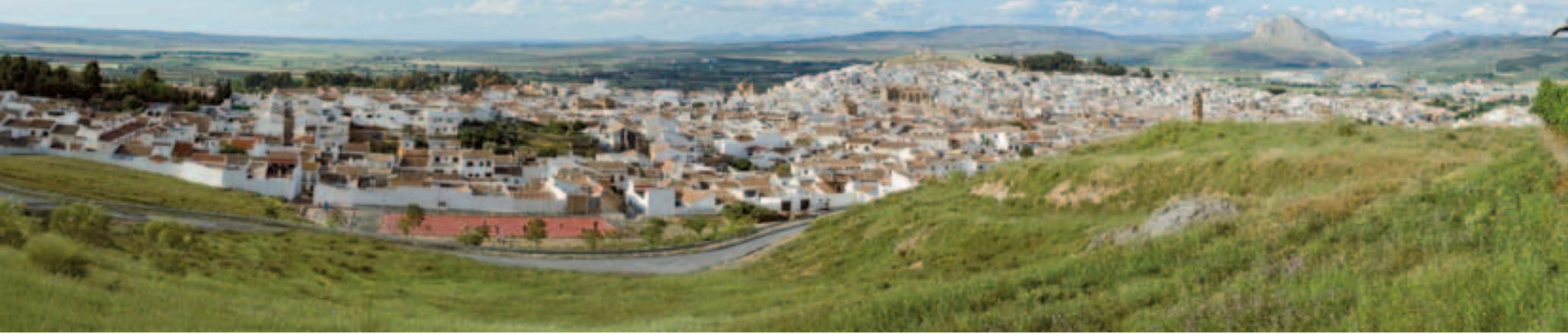

Panorámica de Antequera con la vega y la Peña de los Enamorados al fondo. Foto: Juan Carlos Cazalla, IAPH 


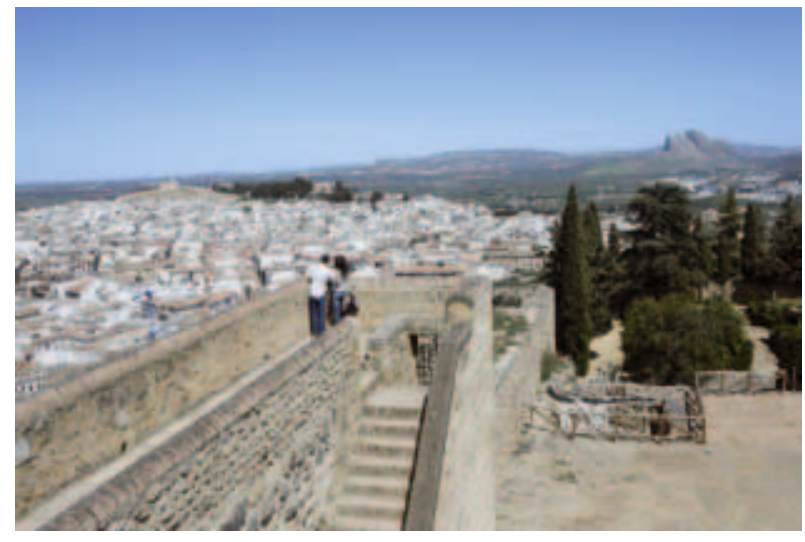

Alcazaba de Antequera. Foto: Juan Carlos Cazalla, IAPH

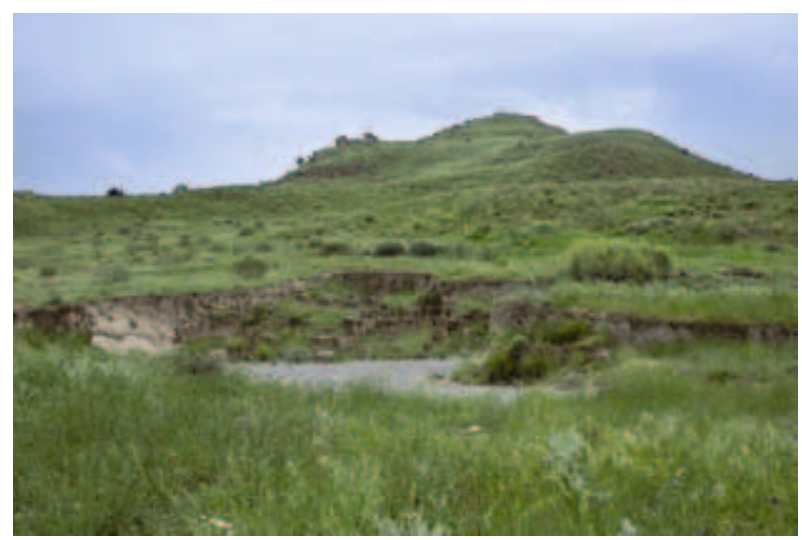

Singilia Barba. Foto: Juan Carlos Cazalla, IAPH
Gráfico 1. Distribución de inmuebles por Tipo de Patrimonio

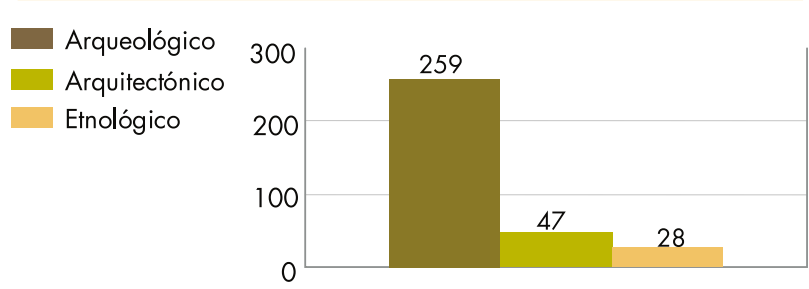

Gráfico 2. Distribución de inmuebles por Tipologías Funcionales
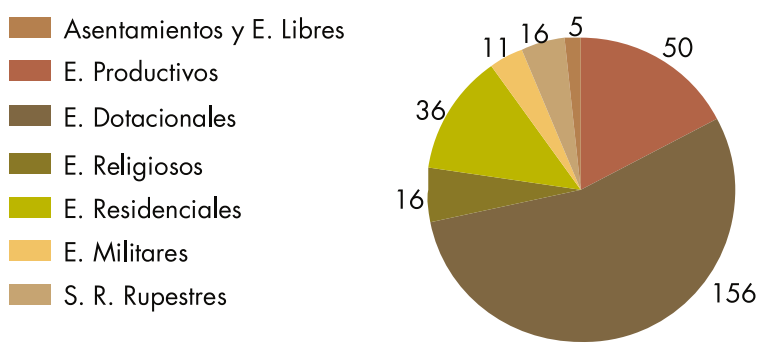

Gráfico 3. Distribución de inmuebles por Periodo Histórico

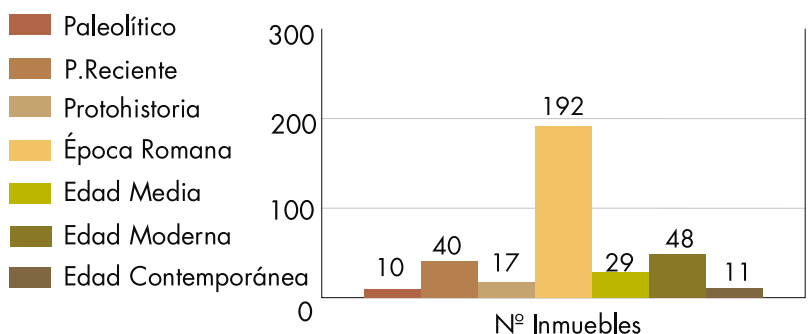

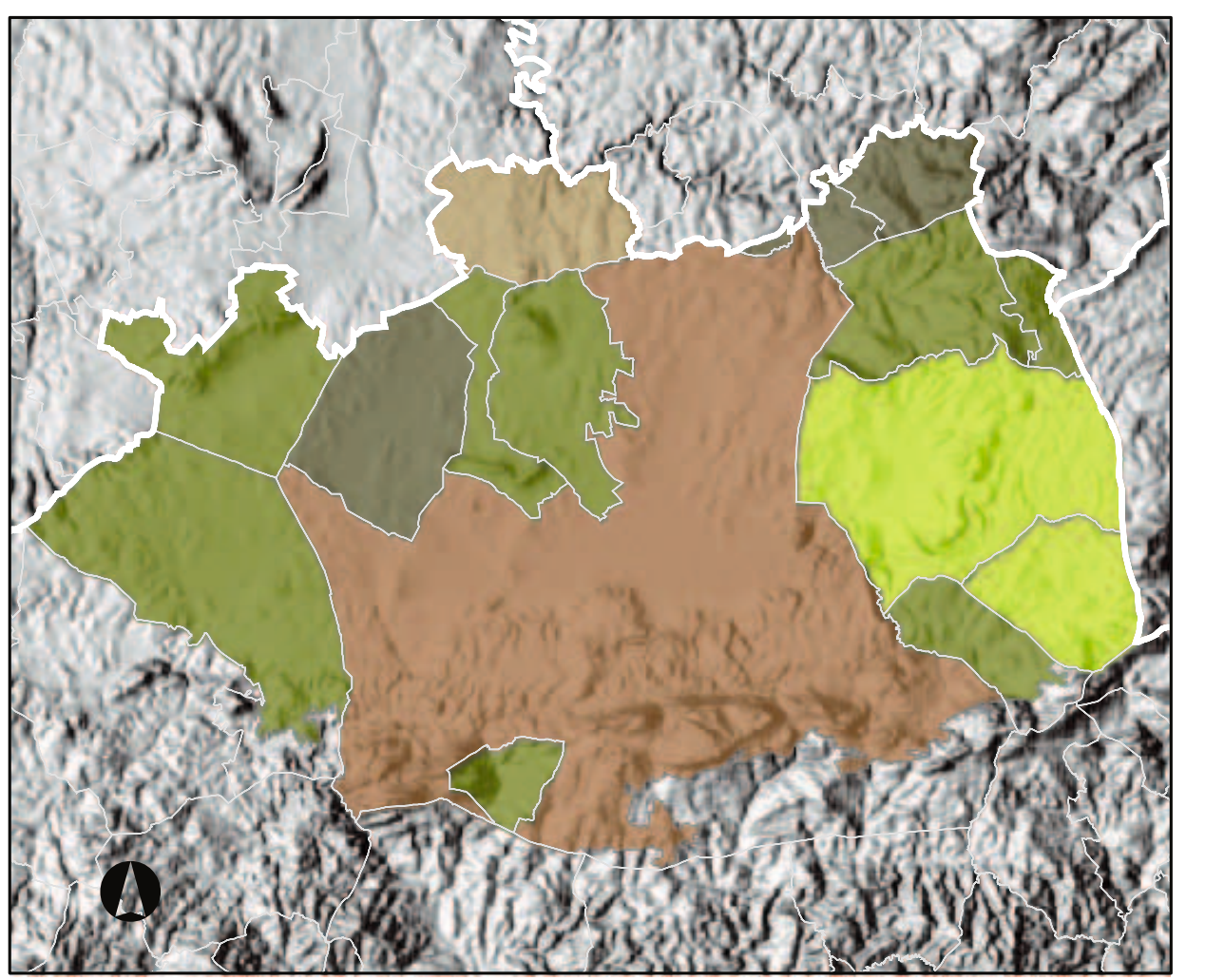

Mapa de distribución del Patrimonio Inmueble.

Antequera y Archidona

Leyenda

Municipios
Límites Provinciales

№ de Inmuebles

$0-3$

$4-14$

$15-36$

$37-77$

$78-133$

\section{Escala 1:500.000}

Proyección UTM USO 30

Localización del área

Antequera y Archidona. Distribución del Patrimonio Inmueble. Mapa y gráficos: Centro de Documentación y Estudios.IAPH

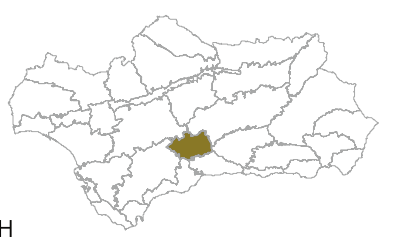

